\title{
Inventory of forest biomass in Brazilian Amazon: a local approach using airborne P-band SAR data
}

\author{
J.R. dos Santos, L.S. Araujo, C.C. Freitas, S.J.S. Sant'Anna, L.V. Dutra, J.C. Mura, F.F.Gama, P.Hernandez Filho \\ National Institute for Space Research - INPE \\ Av. dos Astronautas, 1758 - CEP 12.227-010 São José dos Campos, SP, Brazil \\ Phone: +55-12-345 6427, Fax:+55-12-3456449 \{jroberto@ltid.inpe.br\}
}

\begin{abstract}
The objective of this study is to explore the use of airborne P-band SAR polarimetric data, to stratify biomass by primary and secondary vegetation typology. To ensure that different landscapes of Amazon upland forest are represented, a test-site located in the lower Rio Tapajós region, Pará State, was selected. The backscatter signals derived from the complex image of the P-band SAR were correlated with field data obtained from a forest inventory, for different physiognomic-structural aspects of the tropical rainforest. The estimation of above-ground biomass for these forest types was modeled by $\mathrm{DBH}$ and total height measurements, including the use of general allometric equations. Statistical regression models were applied to establish the relationship between biomass and radar data at $\mathrm{HH}, \mathrm{HV}$ and VV polarization. The overall objective of this $\mathrm{P}-$ band experiment is to improve the regional monitoring process of biomass dynamics as well as landscape changes, due to human action.
\end{abstract}

\section{INTRODUCTION}

The annual rate of deforestation, including timber exploitation in the Brazilian Amazon, has been traditionally estimated using optical sensor data (Landsat/TM). Usually a statistical procedure is used to estimate the disturbance area under clouds, which systematically affect part of the northern region of Brazil. Due to this, SAR images are presently being used associated with data from optical sensors, to characterize the different processes leading to land use in this region. Taking into account the current technological expertise on the estimation of forest biomass, and considering the limitations of $\mathrm{L}, \mathrm{C}$ and $\mathrm{X}$-band data $[1,2,3,4]$, recently a scientific mission was accomplished with $\mathrm{X}$ and $\mathrm{P}$ band SAR polarimetric data acquisition over sections of Brazilian Amazon (September'2000). The SAR data acquisition was performed by AEROSENSING RADARSYSTEME Gmb Company/Germany within cooperation Brazilian Army and INPE, and constitutes the first P band SAR data set over the Brazilian tropical rainforest, in the lower Rio Tapajós region, Pará State. Within this frame, the objective of this study is to know the spectral/structural space of attributes of backscatter values, within primary and secondary forest in P-band SAR images, and its relation to biomass data. This work represents the first results of the experiment mentioned, referring to the potential of P-band, for the support of the inventory of the Amazon Forest. Other themes of interest with SAR data of this campaign are: thematic mapping, elaboration of DEM (with concomitant acquisition of X-band data), analysis of the relations between edaphic/pasture conditions, among other issues.

\section{TEST-SITE DESCRIPTION}

As previously mentioned, the area selected for this study is located at the lower Rio Tapajós region (Pará State), with the geographical coordinates between W $58^{\circ} 50^{\prime} 41.68^{\prime \prime}$ to $59^{\circ} 07^{\prime}$ $57.18^{\prime \prime}$ and S $3^{\circ} 15^{\prime} 19.4^{\prime \prime}$ to $3^{\circ} 15^{\prime} 16.99^{\prime \prime}$ close to the village of São Jorge, along highway BR- 167 Cuiabá-Santarém. The climate is of type Amw according to Köppen, with an monthly rainfall of 1,750 to $2,000 \mathrm{~mm}$ as well as average temperature of. $26^{\circ} \mathrm{C}$. In this study area, the latossol (oxisol) predominates, with occurrence of dense and open tropical forest without palms. Human occupation is related mostly to subsistence agriculture (rice, cassava, maize, beans, pepper are the main products) and specially to huge areas for extensive cattle raising.

\section{MATERIALS AND METHODS}

The airborne SAR images were obtained by a system that acquires both $\mathrm{P}$ (polarimetric) and $\mathrm{X}$ band interferometric data. Technical characteristics of the $\mathrm{P}$ band imaging system: Wavelength $=72 \mathrm{~cm}$; Middle frequency $=415 \mathrm{MHz}$; Polarizations $=\mathrm{HH}, \mathrm{HV}, \mathrm{VH}$ and VV; Depression angle $=$ $45^{\circ}$; Mean flight height $=3,216 \mathrm{~m}$; Range resolution $=1.5 \mathrm{~m}$; Azimuth resolution $=0.7 \mathrm{~m}$, for 1 look slant range image. Topographic maps and Landsat-TM images were used as complementary materials for the registration procedure and selection of sample sites in the field.

The $\mathrm{P}$ band scenes in both complex and amplitude mode were initially analyzed with topographic maps, for the orientation of flight strips, in order to visualize different landscapes and to facilitate plotting of points surveyed during the field campaign. Initially, the images were radiometrically corrected according to the antenna pattern, and afterwards the polarimetric calibration of each channel individually (polarizations) was done. The $\mathrm{P}$ band scenes (Figure 1) were transformed to intensity mode, in order to extract the average values of the digital number from samples. During the field survey, information from different vegetation features (of primary and secondary tropical forest) were collected and 
measurements of $\mathrm{DBH}>5 \mathrm{~cm}$ and tree height were made respectively in lots of 2,500 and $1,000 \mathrm{~m}^{2}$, in order to estimate the biomass through allometric equations. In addition to that, the position of each arboreal individual within each plot and the identification of botanical species was also conducted. During the biomass inventory, a large amount of samples was effectively obtained during the field survey, totaling 33 samples. A partial field data (17 plots) was used in this preliminary study. The precise location of each field plot in the respective radar database was identified using the GPS system. Biomass data collected in the field and backscatter data obtained from P-band scenes were integrated and analyzed together, using regression models.
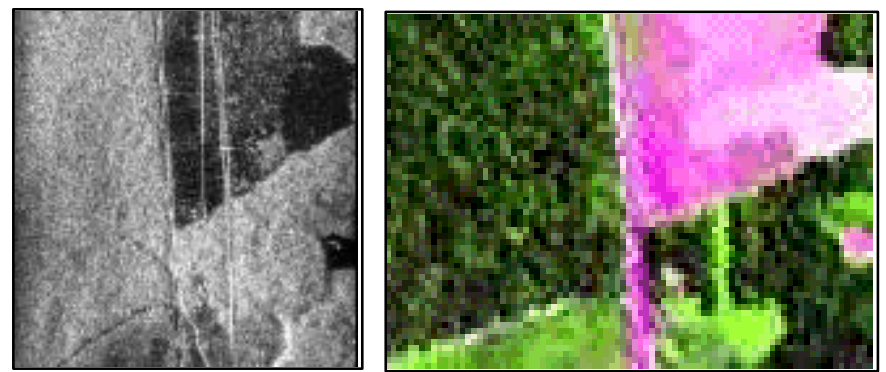

Fig.1. (a) $\mathrm{P}$ band multilook amplitude image $(\mathrm{HH}$ polarization) from September, 2000; (b) color composite of $\mathrm{TM} /$ Landsat-7 image $(5 \mathrm{R}, 4 \mathrm{G}, 3 \mathrm{~B})$ from August, 2000.

\section{RESULTS}

Those plots of secondary succession show mean values of $24.3 \mathrm{ton} / \mathrm{ha}$, where the number of trees per hectare was 1406 with $\mathrm{DBH}>3 \mathrm{~cm}$. This quantitative feature is related to the different stages of regrowth and also to the type and intensity of land use, which determines the degree of soil compaction and as a consequence affects the growth of pioneer species. Those areas of primary forest, present mean values of 189.6 ton/ha, with an average of 1035 individuals/ha, considering a $\mathrm{DBH}>5 \mathrm{~cm}$ and maximum DBH around $42 \mathrm{~cm}$. Three vegetation stores were distinguished on the primary forest: a discontinuous upper canopy ranging from 25 to $30 \mathrm{~m}$, a continuous under-store from 13 to $20 \mathrm{~m}$, and a dense stratum with undergrowth from 6 to $10 \mathrm{~m}$. Figure 2 shows the relation between biomass and gray level values of $P$ band intensity images, obtained from all georeferenced plots distributed in the lower Rio Tapajós region.

From the analysis of Figure 2, one observes a similar behavior of this function with an increase of the grey levels, until a certain saturation point is obtained, that corresponds to higher biomass densities. Some authors [5, 6] mention this point of saturation on $\mathrm{P}$ band data, where the $\mathrm{dB}$ values do not deliver significant information of biomass variation, referring to a biomass of around 100 ton/ha. In this study the radar data showed a high sensitivity of the model for biomass, with a saturation zone of about 150 ton/ha. At the comparative analysis of the three polarizations, one verifies that HV data fits better $\left(r^{2}=0.6475\right)$ to biomass data at this regression function used. The higher $\mathrm{HV}$ response for broadleaf dense forest was probably due to a higher concentration of biomass to the structure of branches/twigs, and a significant diversity of branching angles in this type of vegetation cover in the region. This improved adjustment with polarization $\mathrm{HV}$ was also mentioned by [3], followed by $\mathrm{HH}$ polarization and afterwards VV. The space of attributes of primary and secondary forest formations is well defined at $\mathrm{P}$ band, which was also mentioned in the studies from [6].

\section{CONCLUSIONS}

The conclusions presented here, are the results of a preliminary analysis. Radiometric image calibration of Pband, obtained from information modeled using 6 corner reflectors, installed in the field during the experiment, will be obtained soon. The next step of this study, based on the regression equation that best fits the data set, the biomass intervals can be defined and mapped for all test-sites, as a function of the backscatter values from P-band image in intensity mode. This study can give substantial support to the development of models related to global change studies, because P-band data are promising tools to analyze the high values of biomass, found mainly in tropical forests. This work is a synthetic contribution to the Program of Science and Technology for Environmental Management (PPA 20002003) of the Brazilian Ministry for Science and Technology (MCT), looking for tools aiming to control and monitor environmental issues in the Amazon.

\section{ACKNOWLEDGEMENT}

We acknowledge the CNPq fellowship for authors (process 300677/91-0, 380597/99-3, 300927/92-4) and FAPEMIG (process 00054/00).

\section{REFERENCES}

[1] Dobson, M.C.; Ulaby, F.T.; Le Toan, T.; Beaudoin, A.; Kasischke, E.S.; Christensen, N. 1992. Dependence of radar backscatter on conifer forest biomass. IEEE Transactions on Geoscience and Remote Sensing, vol. 30, $\mathrm{n}^{\circ} 2$, pp. 412-415.

[2] Le Toan, T.; Beaudoin, A.; Riom, J.; Guyon, D. 1992. Relating forest biomass to SAR data. IEEE Transactions on Geoscience and Remote Sensing, vol. 30, $\mathrm{n}^{\circ}$ 2, pp. 403-411.

[3] Imhoff, M.L. 1995. Radar backscatter and biomass saturation: ramifications for global biomass inventory. 
IEEE Transactions on Geoscience and Remote Sensing, vol. $33, \mathrm{n}^{\circ} 2$, pp. 511-518.

[4] Santos, J.R.; Araujo, L.S.; Pardi Lacruz, M.S. 2000. Potential use of JERS-1 data for biomass estimation of the tropical forest environments in Brazilian Amazonia. In: International Geoscience and Remote Sensing
Symposium - IGARSS. Honolulu, Hawaii. July 24-28 ${ }^{\text {th }}$, 2000. Proceedings. (CDROM).

[5] van der Sanden, J.J. 1997. Radar remote sensing to support tropical forest management. Tropenbos-Guyana Series 5. Georgetown, Guyana. 332p. (ISBN 90-5485778-1).
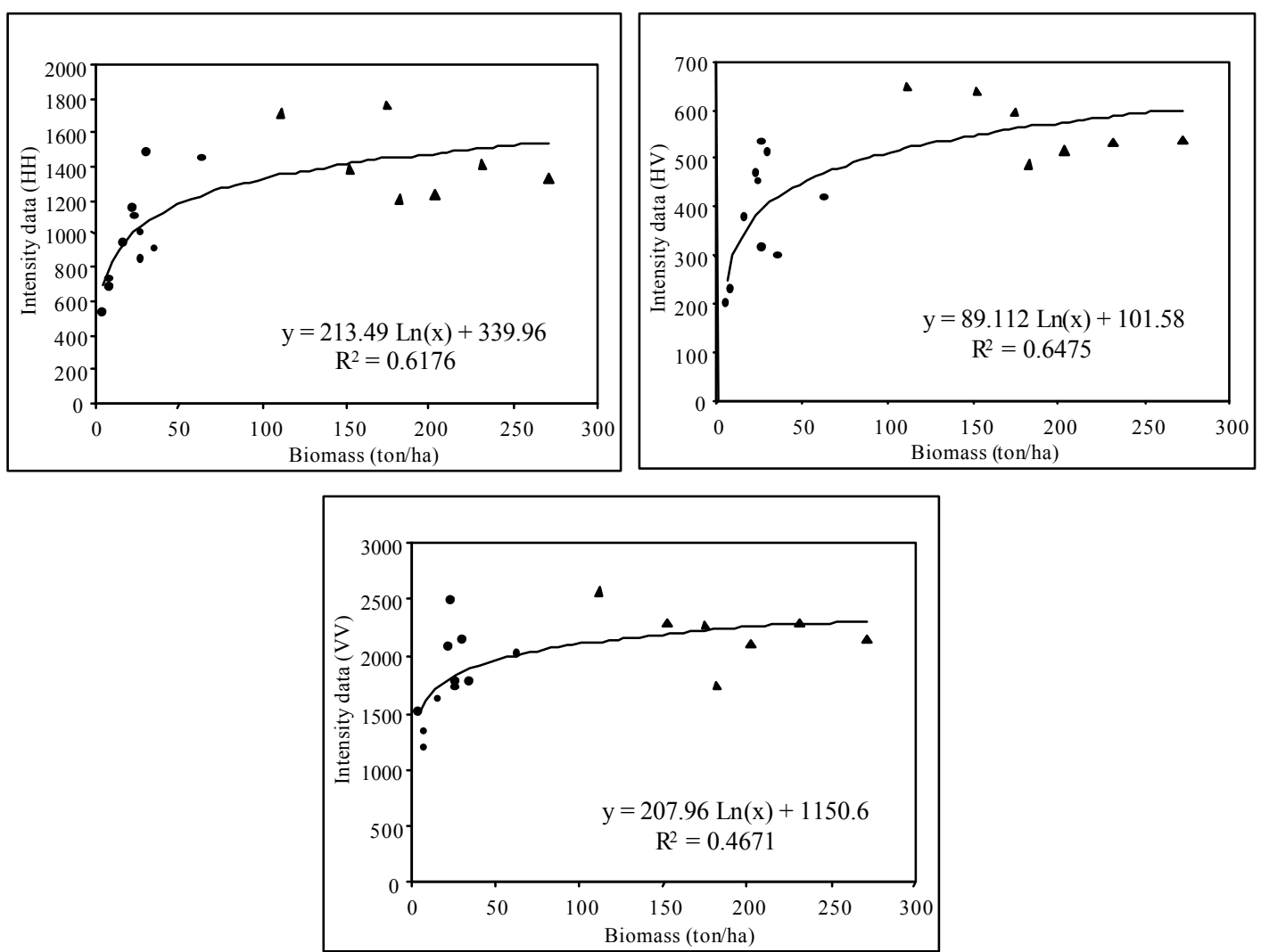

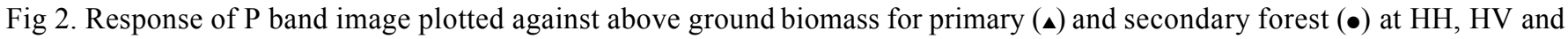
VV polarizations. 